\title{
Prenatal Detection of Fetal Anomalies at the 11- to 13-Week Scan-Part I: Brain, Face and Neck
}

\author{
Waldo Sepulveda, Tamara Illescas, Begona Adiego, Pilar Martinez-Ten
}

\begin{abstract}
In the last 20 years, the role of first-trimester ultrasound screening has expanded from individual calculation of the risk of aneuploidy through measurement of the nuchal translucency to a powerful technique to evaluate important aspects of the fetal anatomy. Traditionally, the full anatomy scan for detection of structural anomalies has been performed in the second trimester of pregnancy. However, with the implementation of the first-trimester scan at 11 to 13 weeks of gestation many of the structural anomalies traditionally detected in the second trimester can now be identified earlier in pregnancy. In the first part of this review we discuss the main ultrasound findings that may facilitate the prenatal detection of fetal brain, face and neck abnormalities in the first trimester of pregnancy.
\end{abstract}

Keywords: Brain malformations, Facial defects, Fetal anomalies, Fetal ultrasound, First-trimester scan, Head malformations, Neck anomalies, Nuchal translucency screening.

How to cite this article: Sepulveda W, Illescas T, Adiego B, Martinez-Ten P. Prenatal Detection of Fetal Anomalies at the 11- to 13-Week Scan-Part I: Brain, Face and Neck. Donald School J Ultrasound Obstet Gynecol 2013;7(4):359-368.

Source of support: This work was supported by an unrestricted research grantfrom the Sociedad Profesional de Medicina Fetal 'Fetalmed', C hile.

Conflict of interest: None declared.

\section{INTRODUCTION}

First-trimester ultrasound screening for chromosomal abnormalities using nuchal translucency (NT) thickness was introduced 20 years ago. ${ }^{1} \mathrm{~A}$ subsequent multicenter screening study involving almost 100,000 women demonstrated that first-trimester ultrasound examination at 11 to 13 weeks of gestation is an important tool for the screening of chromosomal abnormalities. ${ }^{2}$ With major improvements in image resolution and a better systematic anatomic assessment protocol, ultrasound evaluation of the early fetal anatomy with greater detail is now achievable, making the detection of several structural anomalies possible at this stage of pregnancy. ${ }^{3-5}$

With recent advances in noninvasive prenatal testing using cell-free fetal DNA in maternal blood obtained in early pregnancy, ${ }^{6}$ it is expected that the role of NT screening for the early detection of aneuploidy will become less important than currently is. However, as increased NT thickness is also an important marker for structural abnormalities, ${ }^{7}$ this ultrasound marker will still have an important role for determining which fetuses with normal karyotype are candidates for a targeted ultrasound examination in early pregnancy. Similarly, the 11- to 13-week scan will probably become an important tool for assessing the early fetal anomaly in the low-risk population and, therefore, the detection of structural defects not associated with aneuploidy will become a major goal of the first-trimester scan.

Traditionally, most of the congenital abnormalities have been diagnosed in the second trimester of pregnancy. However, with the increasing incorporation of the 11- to 13-week scan into clinical practice, this examination is progressively used for performing an early anatomy scan. This is not only done at tertiary referral centers but also in less sophisticated centers so every sonographer, obstetrician or radiologist performing obstetric ultrasound scan should be familiar with the normal anatomical findings and the ultrasound features of the most common anomalies potentially diagnosable at this early gestational age. The aim of this article was therefore to review the first-trimester diagnosis of structural defects and to provide the clinician with illustrative material to be used in their daily clinical practice, focusing on those condition affecting the fetal brain, face and neck.

\section{FIRST-TRIMESTER ANATOMY ASSESSMENT}

Several studies have pointed out the utility of a standardized ultrasound protocol to evaluate the fetal anatomy in early pregnancy, with notable detection rates for the most severe malformations..$^{8-10}$ Table 1 shows a simplified ultrasound protocol that could be useful when evaluating the fetal anatomy at the 11- to 13-week scan.

\section{CRANIAL AND BRAIN ABNORMALITIES}

The brain is the most prominent fetal organ and, as such, it is easily accessible for examination during the first-trimester anatomy scan. N evertheless, it should be bear in mind that even at the end of the first trimester it is a relatively small, underdeveloped structure and careful examination is still required for the detection of nonobvious central nervous system (CNS) anomalies. Examination of the brain should include the skull shape and the membranous gaps between the cranial bones such as fontanelles and sutures. A lthough routine examination of fontanelles and sutures is not part of the first-trimester scan, the metopic suture is recognized 
Table 1: Suggested ultrasound protocol for the first-trimester anatomy scan

\begin{tabular}{|c|c|c|}
\hline Fetal region & Anatomic structures to be evaluated & Structural anomalies potentially recognizable \\
\hline Head & $\begin{array}{l}\text { Ossification of the cranium, choroid plexuses, } \\
\text { midline, thalami, posterior fossa } \\
\text { (fourth ventricle and cisterna magna) }\end{array}$ & $\begin{array}{l}\text { Acrania/anencephaly sequence, cephalocele, } \\
\text { holoprosencephaly, posterior fossa cyst, ventriculomegaly }\end{array}$ \\
\hline Face & $\begin{array}{l}\text { Profile, nasal bone, orbits, hard palate, } \\
\text { mandible, retronasal triangle }\end{array}$ & $\begin{array}{l}\text { Cleft lip/palate, cyclopia/proboscis, micrognathia, } \\
\text { midfacial hypoplasia }\end{array}$ \\
\hline Neck & Nuchal translucency (NT) & $\begin{array}{l}\text { Increased Nuchal translucency, cystic hygroma, distended } \\
\text { jugular lymphatic sacs }\end{array}$ \\
\hline Spine & Curvature, overlying skin & $\begin{array}{l}\text { Kyphoscoliosis (including VATER association and body stalk } \\
\text { anomaly), spina bifida }\end{array}$ \\
\hline Thorax & $\begin{array}{l}\text { Cardiac position, four-chamber view, } \\
\text { outflow tracts, lungs, diaphragm }\end{array}$ & $\begin{array}{l}\text { Cardiac defects, ectopia cordis (isolated or in association with } \\
\text { anterior wall defects), pleural effusion, diaphragmatic hernia }\end{array}$ \\
\hline Abdomen & $\begin{array}{l}\text { Stomach, kidneys, bladder, insertion of } \\
\text { the umbilical cord in the anterior abdominal wall }\end{array}$ & $\begin{array}{l}\text { Gastroschisis, omphalocele, hydronephrosis, megacystis, } \\
\text { abdominal cysts }\end{array}$ \\
\hline Limbs & Hands, feet, limb segments and position & Missing limb, limb reduction defects, polydactyly, talipes \\
\hline $\begin{array}{l}\text { Placenta and } \\
\text { umbilical cord }\end{array}$ & $\begin{array}{l}\text { Placental location and echogenicity, cord } \\
\text { vessels, insertion of the cord in the placental mass }\end{array}$ & $\begin{array}{l}\text { Placental cysts, molar placenta, single umbilical artery, cord } \\
\text { cysts, marginal and velamentous insertions }\end{array}$ \\
\hline
\end{tabular}

as an important ultrasound landmark as the frontal bones should not be visualized in the exact midsagittal plane of the fetal head when the NT and nasal bones are evaluated. ${ }^{11}$ In this very same sagittal plane, important cerebral midline structures should be also identified including the thalamus, midbrain, brainstem, medulla oblongata as well as the fourth ventricle (also called intracranial translucency) and cisterna magna (Fig. 1). ${ }^{12}$ The metopic suture and lower aspect of the frontal fontanelle are also easily identifiable in the coronal plane of the face at the level of the retronasal triangle view above the nasal bones ${ }^{13,14}$ (see below). On the other hand, the axial plane of the brain is usually visualized to measure the biparietal diameter (BPD) at the level of the thalami. ${ }^{15} \mathrm{~T}$ wo additional axial sections are also important; one is at the level of the choroid plexuses, which is slightly cranial and parallel to the transthalamic view, and the other is at the level of the posterior fossa, which is obtained by angulating the transducer posteriorly from the transthalamic view. The choroid plexuses are very large in the first trimester and, in an axial section, display a characteristic butterfly-shaped image (Fig. 2). ${ }^{16}$ This view provides important information regarding the cleavage of the prosencephalon, as the presence of the 'butterfly' sign rules out a serious condition, such as holoprosencephaly by demonstrating the midline and two lateral cerebral ventricles.

\section{Acrania/Anencephaly Sequence}

Open neural tube defects are severe congenital anomalies occurring with a prevalence of one in 1,000 to 2,000 pregnancies. A mong them, the acrania/anencephaly or exencephaly/anencephaly sequence is the most severe CNS malformation, which is characterized by complete absence

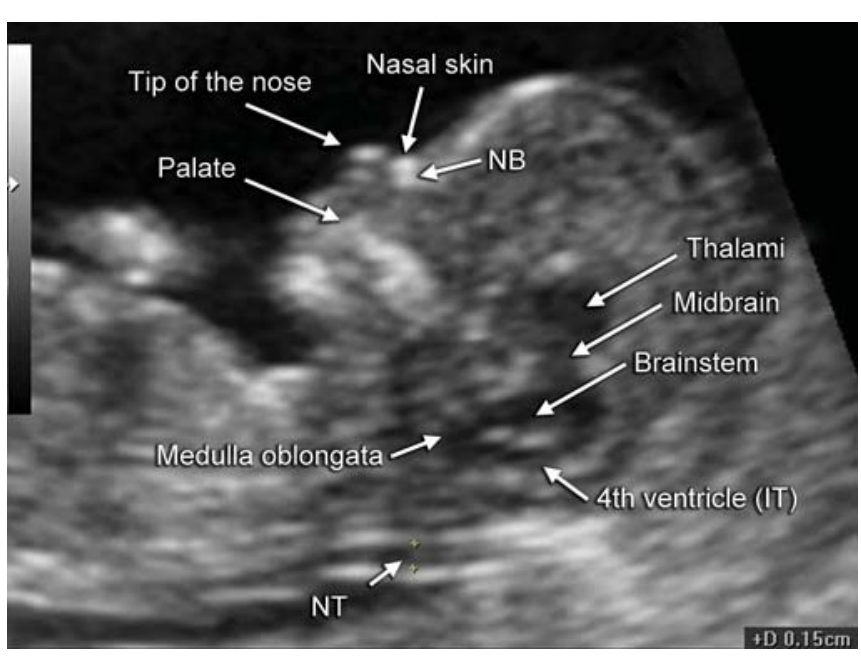

Fig. 1: Normal first-trimester anatomic features of the fetal brain, face and neck as depicted by two-dimensional ultrasound from the midsagittal section of the head. IT: intracranial translucency; NB: nasal bone; NT: nuchal translucency
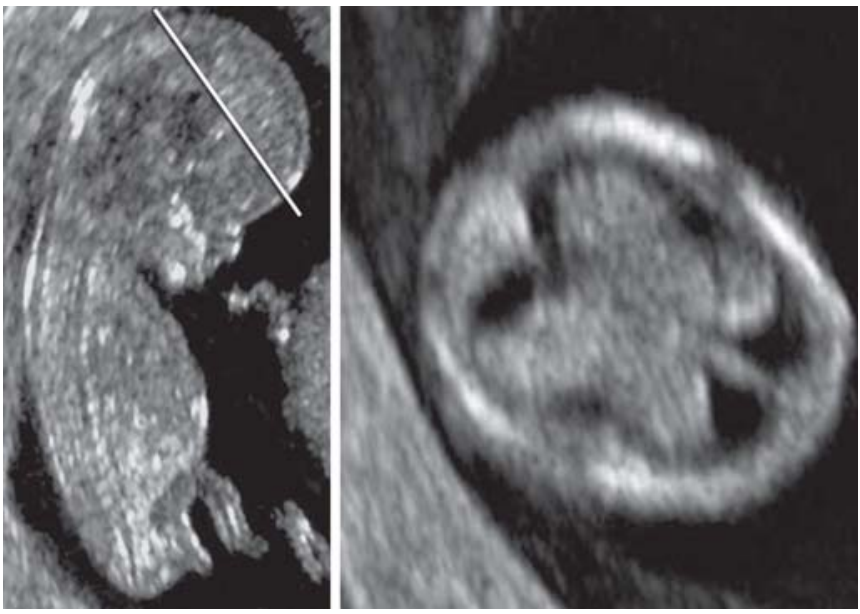

Fig. 2: Axial view of the fetal brain shows the prominent choroid plexuses filling the ventricles ('butterfly' sign) in a normal firsttrimester fetus. The left panel shows the level at which this transverse section is obtained 

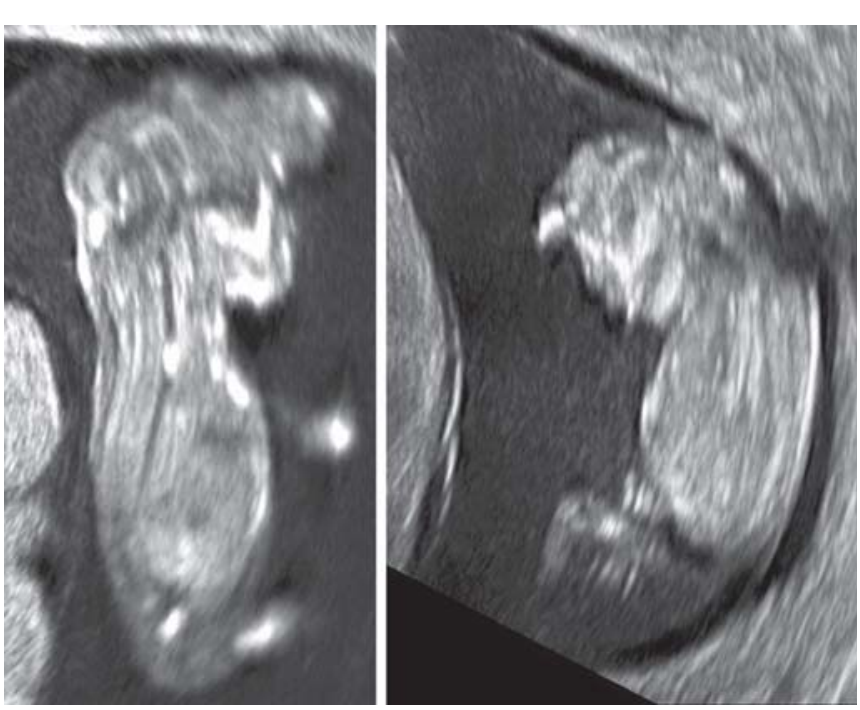

Fig. 3: Acrania/anencephaly sequence at 11 weeks (left panel) and at 13 weeks (right panel). Note echogenic amniotic fluid and absent cranial bones with progressive reduction of the amount of brain tissue

of the calvarium leading to progressive destruction of the brain tissue. ${ }^{17,18}$ In the second trimester of pregnancy, anencephaly is easily diagnosed by the detection of absent cranial vault and cerebral hemispheres. However, in the first trimester the diagnosis could be difficult, especially if a large amount of brain tissue remains intact at the time of ultrasound examination. ${ }^{19}$ The ultrasound spectrum of acrania/anencephaly sequence varies widely, with the cardinal sign being an absent calvarium with persistence of different amount of brain tissue (Fig. 3). In about one-quarter of cases, the ultrasound presentation includes a relatively normal-appearing, well-preserved brain, in which only the calvarium is absent. In the remaining $75 \%$ of the cases, different degrees of destruction and vacuolization of the brain are evident, ranging from disorganized brain structures but still parts of the cerebral hemispheres being present (the 'M ickey mouse' sign) ${ }^{20}$ to complete or almost complete absence of the brain. Invariably, the crown-rump length in these fetuses is getting smaller as pregnancy progresses. ${ }^{18-20}$

The acrania/anencephaly sequence is primarily due to failure of closure of the cranial portion of the neural tube. However, it can also be associated with other conditions such as amniotic band syndrome; in such cases an amniotic band, or even the placenta, can be identified attached to the cranium (Fig. 4). In addition, as progressive destruction of the brain tissue occurs, the amniotic fluid can be visualized as more echogenic than the fluid in the extracelomic space, in clear contrast to what happens in normal conditions in which the extracel omic fluid is usually more echogenic than the amniotic fluid. ${ }^{21}$ In contrast to the finding from TimorTritsch et al, ${ }^{17}$ who found clear amniotic fluid on

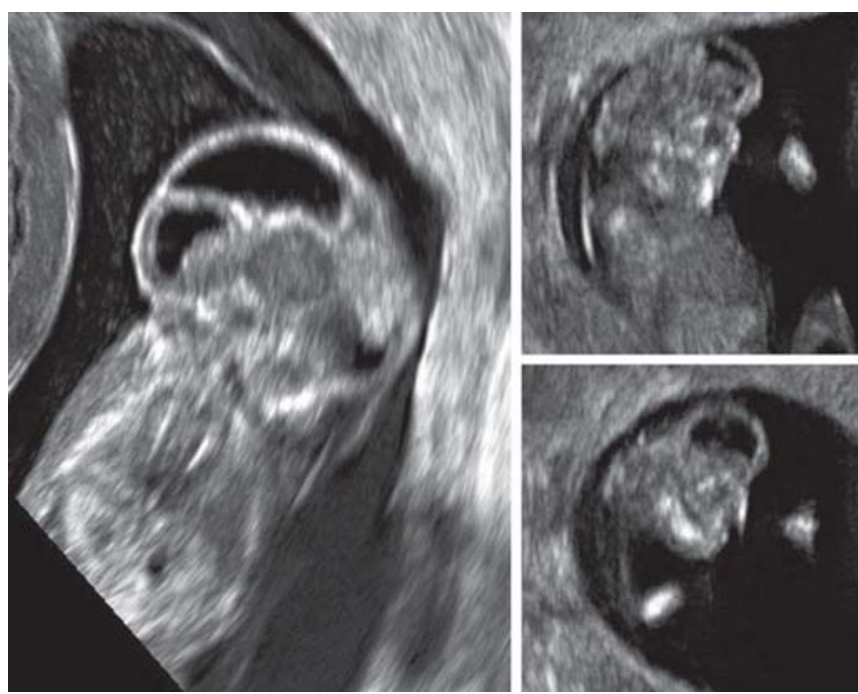

Fig. 4: Acrania/anencephaly sequence associated to amniotic band syndrome. Note different degrees of vacuolization of the brain tissue secondary to persistence of the meningeal coverings
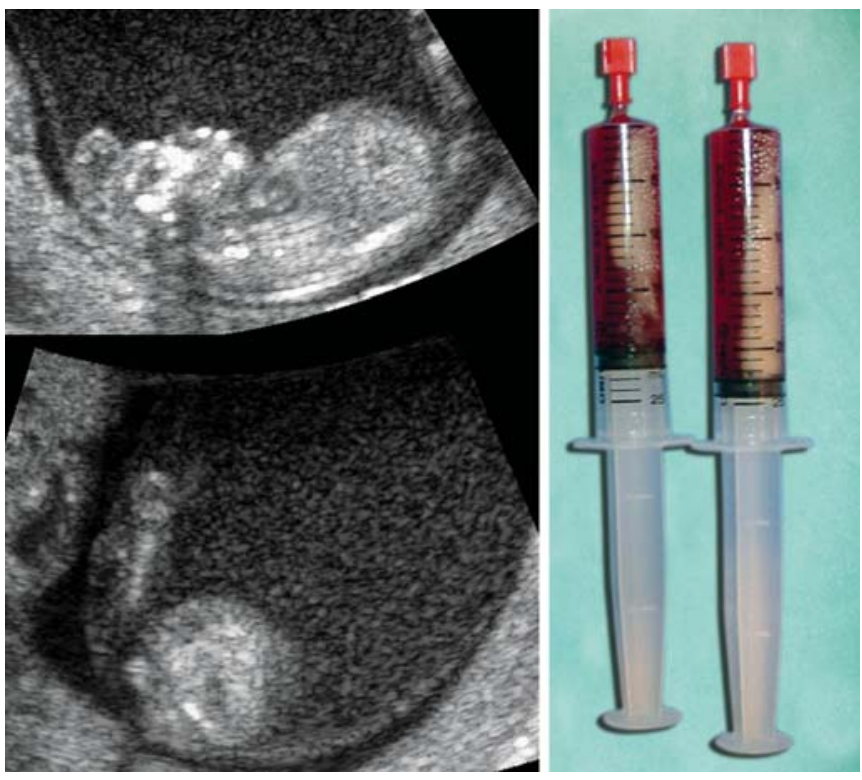

Fig. 5: Echogenic amniotic fluid in a first-trimester fetus with acrania/ anencephaly sequence (left panel). Note the clear contrast with the extracelomic fluid. Amniocentesis for fetal karyotyping revealed intra-amniotic bleeding (right panel)

amniocentesis in these cases, we confirm that the echogenic fluid is due to intra-amniotic bleeding (Fig. 5), but it is still unknown why significant bleeding from brain trauma does not lead to early intrauterine death in these cases.

\section{Cephalocele}

Cephaloceles are serious CNS malformations characterized by partial protrusion of the brain through a cranial defect. L arge- and medium-sized defects can be easily diagnosed by examining the cranial contour in the first trimester, at which time brain tissue outside the cranial cavity can be 
demonstrated (Fig. 6). The prenatal detection of cephalocele in early pregnancy has significant clinical implications. First, it can be associated with a lethal autosomal recessive condition known as M eckel-Gruber syndrome, which is characterized by the triad of cephalocele, polycystic kidneys and polydactyly (Fig. 7). ${ }^{22}$ Due to the normal amount of amniotic fluid in early pregnancy, the diagnosis is easier to establish in the first than in the second trimester, as progressive oligohydramnios frequently makes the detection of this condition more difficult later on in pregnancy. Therefore, examination of the fetal kidneys in the first trimester should be mandatory to determine whether or not the kidneys are involved. Once M eckel-Gruber syndrome has been ruled out, careful examination of the fetus is important to diagnose if the cephalocele is an isolated defect or associated with other anomalies. Associated anomalies are usually found in the context of disruptive defects, i.e. amniotic band syndrome, and they are invariably associated with a dismal prognosis, whereas isolated defects have different prognosis depending on the cephalocele content.

\section{Holoprosencephaly}

Holoprosencephaly is a severe CNS anomaly caused by an abnormal cleavage of the prosencephalon, the most cranial primary cerebral vesicle that plays a critical role in the subsequent development of the thalamus, cerebral

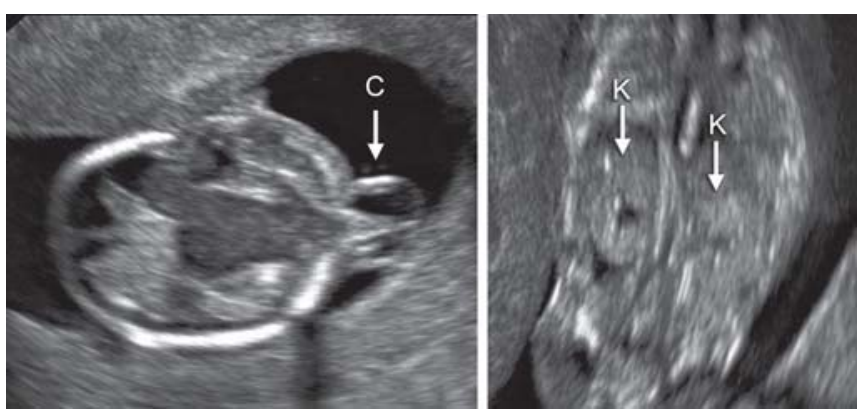

Fig. 6: Isolated cephalocele in a 12-week fetus. Transvaginal scan revealed brain tissue protruding from a defect in the occipital bone ( $\mathrm{C}$, left panel). Examination of abdomen revealed normal kidneys (K, right panel), ruling out Meckel-Gruber syndrome
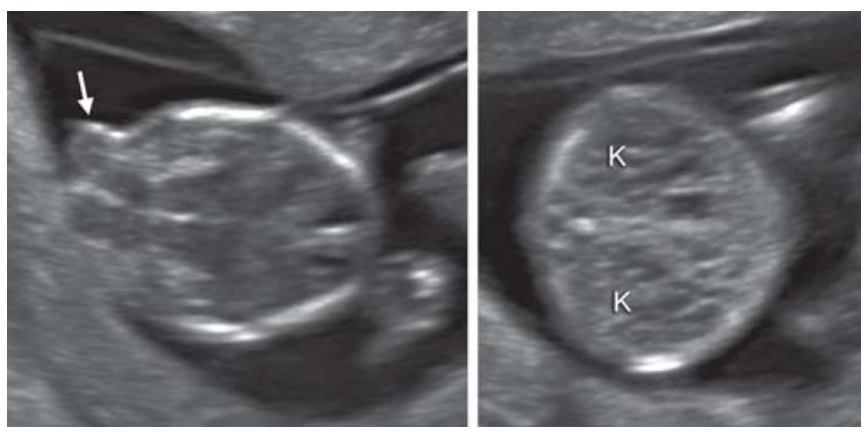

Fig. 7: Occipital cephalocele in a fetus with Meckel-Gruber syndrome (left panel). Note bilateral polycystic kidneys (K, right panel) and normal amniotic fluid hemispheres and face. ${ }^{23}$ Therefore, failure in the cleavage of this vesicle will result in severe abnormalities affecting the uppermost segment of the head. Holoprosencephaly is classified into lobar, semilobar, and alobar types. The semilobar and alobar types are the most severe ones and are amenable to be diagnosed in the first trimester. ${ }^{24}$ Cases of lobar holoprosencephaly, on the other hand, are difficult to diagnose even in the second and third trimester. Indeed, there are no reported cases to date documenting the diagnosis of lobar holoprosencephaly in the first trimester. Characteristic first-trimester ultrasound features of alobar and semilobar holoprosencephaly include inability to demonstrate the 'butterfly' sign, absence of the midline, and the presence of a monoventricular anterior cerebral cavity in association with fused thalami (Fig. 8). ${ }^{16,24}$ A small biparietal diameter as an early sonographic feature of holoprosencephaly has been recently emphasized. ${ }^{24}$ Prenatal karyotyping should be considered in these cases due to the strong association with chromosomal abnormalities, particularly trisomy $13 .^{24}$

\section{Posterior Fossa Anomalies}

Posterior fossa abnormalities, including the $D$ andy-W alker malformation and Dandy-W alker variant, have been rarely reported in the first trimester. ${ }^{25,26}$ How ever, recent interest in the systematic examination of the posterior fossa, triggered by the description of the intracranial translucency, ${ }^{12}$ has resulted in an increasing number of fetuses with posterior fossa malformations being diagnosed early in pregnancy. ${ }^{27-30}$ Care should be taken when evaluating the cerebellum in early pregnancy with high-resolution transvaginal probes as the vermis is not fully developed at this stage and can give the wrong impression of a vermian defect. $^{31,32}$ On the other hand, cysts of the posterior fossa can be easily detected in the first trimester if they are big and should be demonstrated in both the sagittal and axial planes (Fig. 9) to avoid pitfalls caused by shadowing artifacts from the occipital or parietal bones over the posterior fossa. Recently, three-dimensional ultrasound has been used to
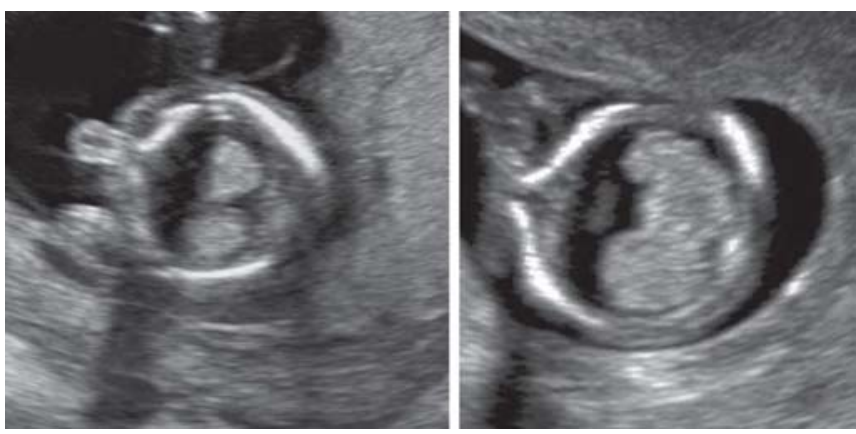

Fig. 8: Holoprosencephaly in two different first-trimester fetuses demonstrating absent of the 'butterfly' sign (for comparison with normal, see Fig. 2), absent midline, and an anterior cerebral monoventricular cavity. Note proboscis in the fetus on the left panel 

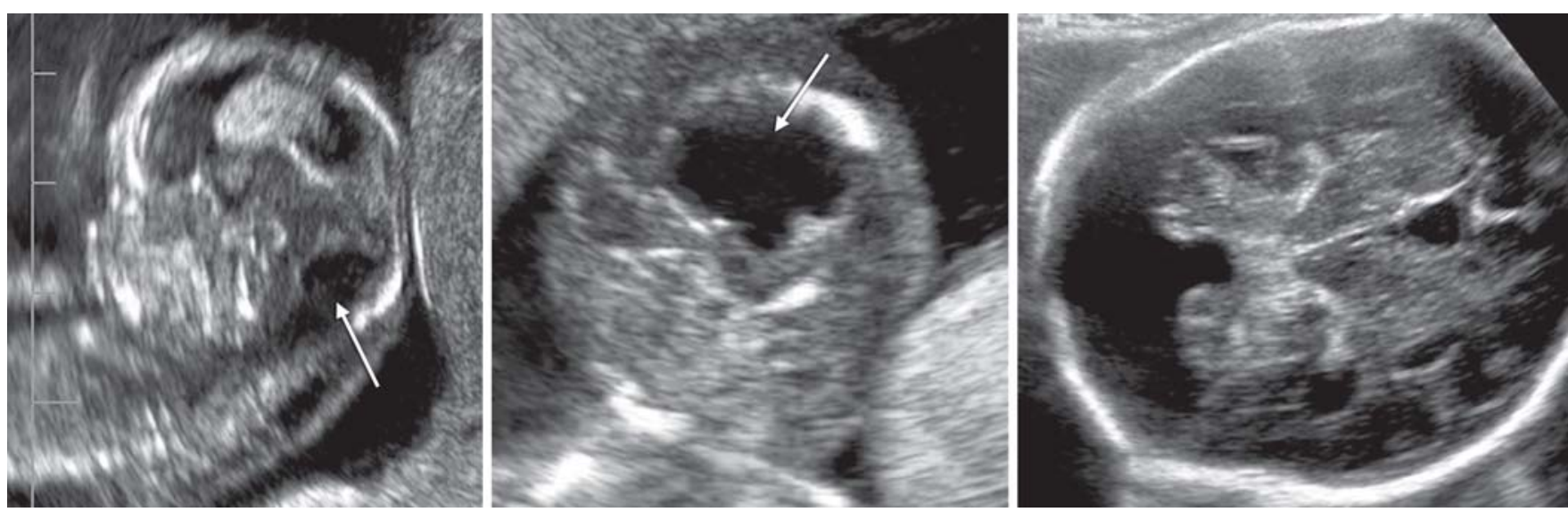

Fig. 9: Dandy-Walker malformation. Note enlarged fourth ventricle (arrow, left panel) and posterior fossa cyst (arrow, middle panel) at 13 weeks. At 32 weeks the enlarged cisterna magna and cerebellar vermian defect is evident (right panel)

examine the choroid plexus of the fourth ventricle. In normal first-trimester fetuses, a clear separation between the fourth ventricle and cisterna magna is clearly seen whereas in fetuses with posterior fossa cystic malformation the choroid plexus is absent or interrupted in the midline, creating a large communication between the fourth ventricle and cisterna magna, which is visible on ultrasound in early pregnancy. ${ }^{33}$

\section{Ventriculomegaly and Hydrocephaly}

These conditions are rarely diagnosed in the first trimester. However, we have noted that they are frequently seen in association with triploidy. In these cases, head-to-abdomen disproportion is also evident even at this gestational age (Fig. 10). ${ }^{34}$ To date, no normative data are available in regard to the size of the lateral cerebral ventricles in the first trimester, so the diagnosis should be established on subjective criteria. Recently, three-dimensional ultrasound has been used to determine the normal width of the lateral cerebral ventricles in normal and aneuploid fetuses; mild ventriculomegaly has been noted in fetuses with trisomy 13 and $18 .{ }^{35}$ However, from the diagnostic point of view, the detection of other evident ultrasound features in association with these aneuploidies would probably make the demonstration of ventriculomegaly in these cases very limited.

\section{FETAL FACE}

$V$ isualization of the fetal face is an integral part of firsttrimester ultrasound screening for chromosomal anomalies, as the midsagittal view of the face is mandatory to obtain a reproducible image of the NT and nasal bones. ${ }^{36}$ On the other hand, first-trimester diagnosis of orofacial malformations, such as cleft lip and palate, has been rarely reported probably because routine assessment of the face for these conditions is difficult due to the small size of the facial structures. Indeed, before 2010 only two cases of bilateral

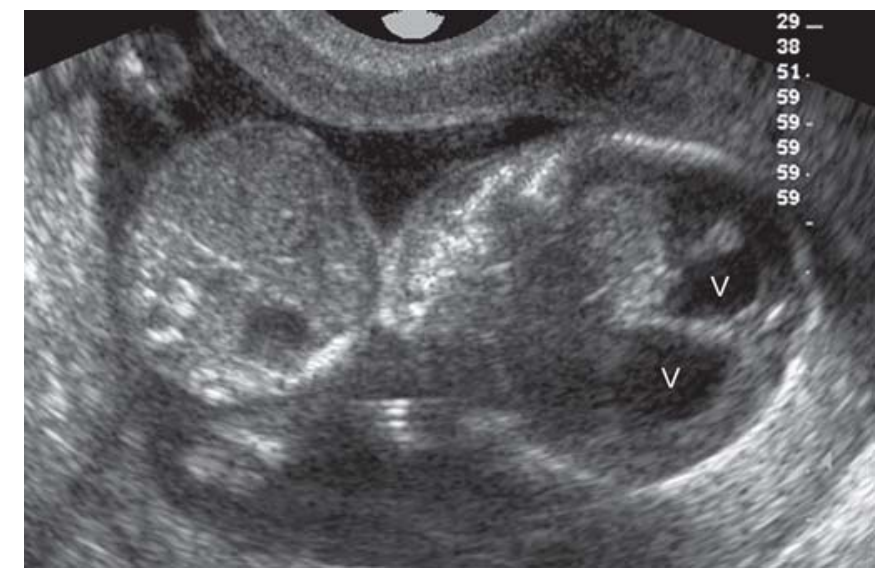

Fig. 10: Transvaginal scan at 14 weeks shows ventriculomegaly (V) in a triploid fetus. Note severe head-to-abdomen disproportion

cleft lip and palate had been reported 37,38 in contrast to the very large numbers of trisomy 21 detected, despite the fact that these two conditions have a similar prevalence in the general population. This can be taken as evidence that although visualization of the fetal head in the sagittal plane is extremely useful for the screening of aneuploidy, it is not the case for the detection of orofacial anomalies. We have recently described an alternative technique for the eval uation of the midface in the first trimester, i.e. the assessment of the coronal plane for the visualization of the maxilla, which displays a characteristic echogenic image that was termed the retronasal triangle. ${ }^{13} \mathrm{This}$ is formed by the primary palate on its base and both frontal processes of the maxilla on the sides (Fig. 11). In addition, the nasal bones can be also identified on the top of the triangle, making this view another useful technique for visualizing the nasal bones in the ultrasound screening of aneuploidy. ${ }^{14,39}$

\section{Midfacial Hypoplasia}

M idfacial hypoplasia is frequent in fetuses with trisomy 21. This is clinically evidenced by demonstrating absent or 

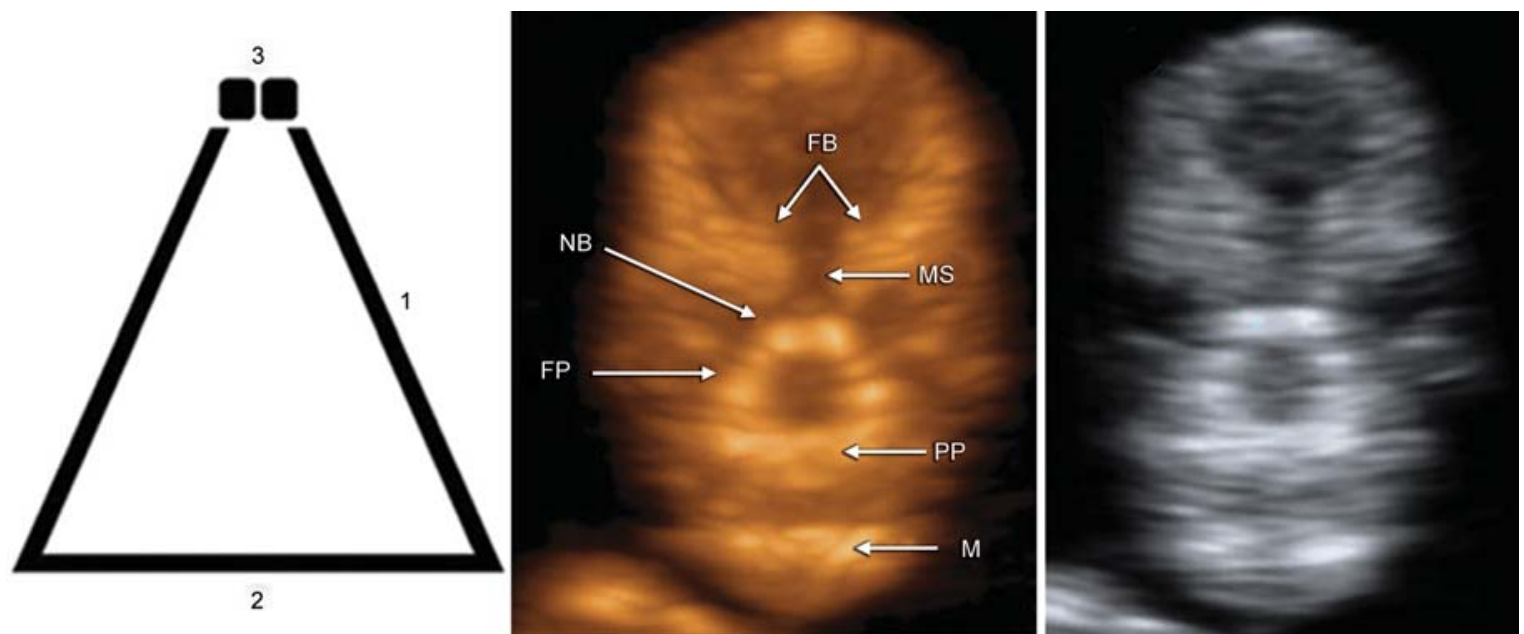

Fig. 11: Retronasal triangle. Left panel: schematic view of the retronasal triangle shows the frontal processes of the maxilla (1) the primary palate (2) and the nasal bones (3) middle and right panel: ultrasound view of the retronasal triangle. FB: frontal bones; MS: metopic suture; NB: nasal bones; FP: frontal process of the maxilla; PP: primary palate; M: mandible

hypoplastic nasal bones. Midfacial hypoplasia is also associated with an abnormal frontomaxillary facial angle, ${ }^{40,41}$ al though this technique is difficult to implement, is more accurate if offline reformatting of three-dimensional data sets are analyzed, and requires a significant expertize to be obtained. Severe midfacial hypoplasia is also seen in fetuses with holoprosencephaly, especially when a large cleft palate is present (Fig. 12).

\section{Cleft Lip and Palate}

The incidental detection of cleft lip and palate diagnosed in the first trimester has been reported. ${ }^{37,38}$ First-trimester fetuses with bilateral cleft lip and palate present with a characteristic premaxillary protrusion as second-trimester fetuses do (Fig. 13). This finding is evident in the first trimester only if a detailed examination of the fetal profile is undertaken. How ever, first-trimester fetuses with a medial facial cleft present with a flat profile and, therefore, the
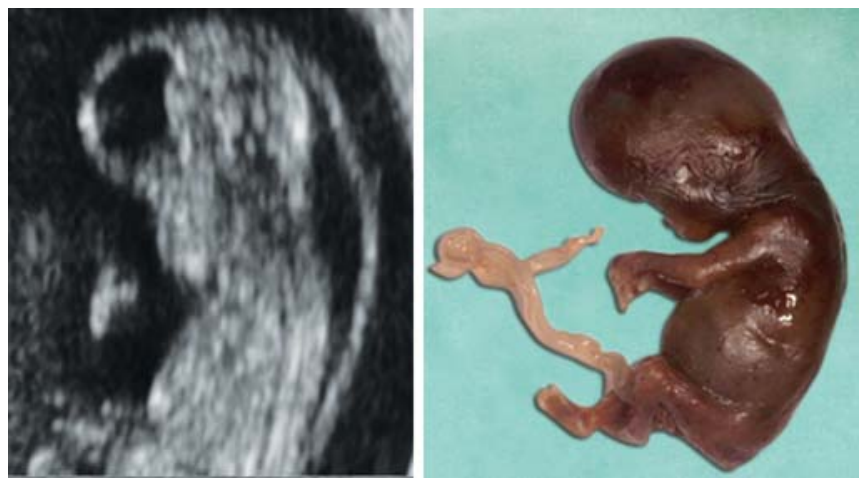

Fig. 12: Severe midfacial hypoplasia in an 11-week fetus with holoprosencephaly (left panel). Postmortem examination confirmed the prenatal diagnosis (right panel)

diagnosis can be easily missed. Differentiation between these two entities is important as in the latter cases they are almost invariably associated with lethal aneuploidies. ${ }^{42}$ Detailed examination of the fetal face is also important in first-trimester fetuses with increased NT, as the prevalence

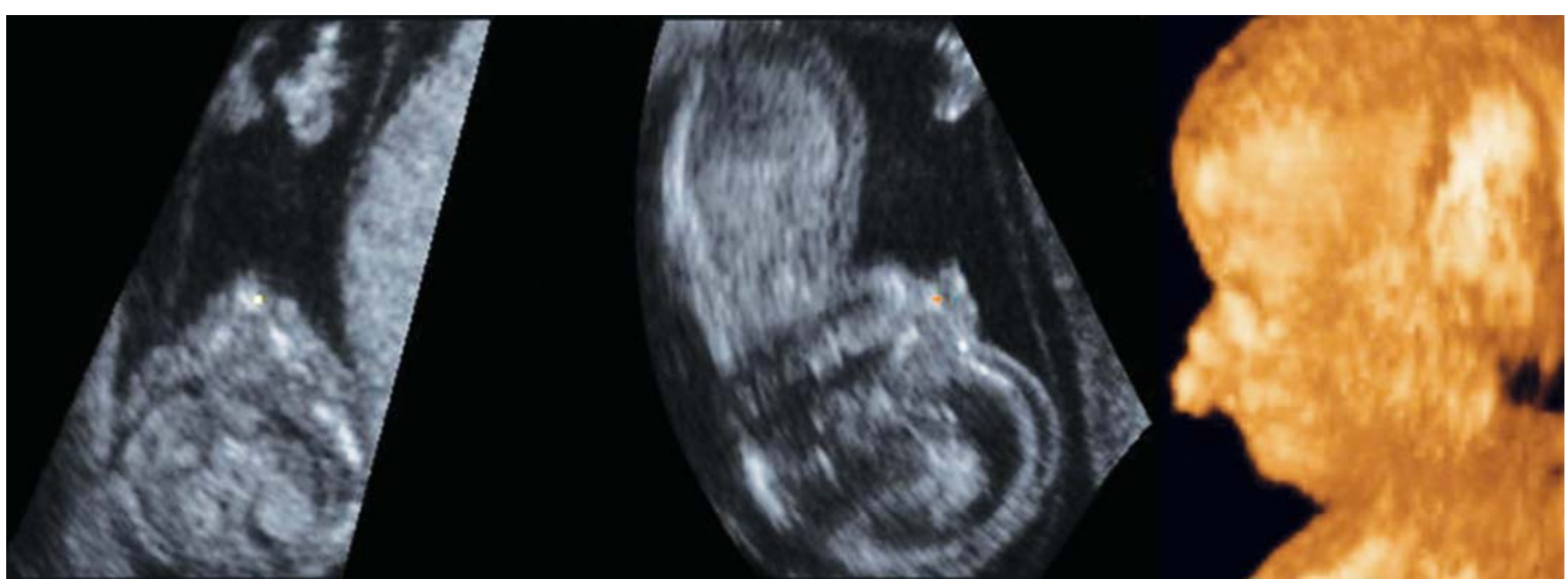

Fig. 13: Bilateral cleft lip and palate in a 13-week fetus. Note premaxillary protrusion 
of cleft lip and palate in these cases is significantly increased in comparison to fetuses with normal NT thickness. ${ }^{43}$

A more systematic approach for the early diagnosis of cleft lip and palate using two- and three-dimensional ultrasound has been reported by our group. ${ }^{13,44} \mathrm{This}$ technique relies on the assessment of the coronal plane of the face focusing on the base of the retronasal triangle for the evaluation of the primary palate. ${ }^{13}$ First-trimester fetuses with cleft of the primary palate present with a gap at the base of the retronasal triangle (Fig. 14). However, a falsepositive diagnosis of $1 \%$ have been described, which has been attributed to shadowing artifacts from the limbs over the fetal face. ${ }^{44} O \mathrm{n}$ the other hand, fetuses with cleft of the secondary palate can be identified using the axial plane, which assessment can be greatly facilitated with the adjunct use of new three-dimensional algorithms, such as the V olumeNT and OmniView softwares. ${ }^{45,46}$ Clefts of the secondary palate can also be demonstrated by examining the axial plane of the head at the level of the hard palate with two-dimensional ultrasound. As all clefts of the secondary palate are medial, an important clue is the identification of an abnormal hard palate on the standard midsagittal plane of the head.

\section{Micrognathia}

Micrognathia is a rare facial malformation characterized by a small, underdeveloped mandible. It represents a prominent feature in a number of chromosomal and genetic syndromes including the Robin anomaly, acrofacial dysostosis, orofacial-digital syndrome, trisomy 18 and triploidy. The prenatal diagnosis of severe micrognathia in a first-trimester fetus with Pierre-R obin syndrome has been reported. ${ }^{47} \mathrm{H}$ owever, the diagnosis in less severe cases relies on subjective criteria by examining the fetal profile to identify the receding chin (Fig. 15). A $n$ alternative technique is the examination of the fetal face using the retronasal triangle view. In this view, normal fetuses display a gap between the two mandibular bones, the so-called mandibular gap, whereas fetuses with micrognathia devoid this gap or the mandible cannot be identified at this level (Fig. 16). ${ }^{48}$

\section{Cyclopia and Proboscis}

Holoprosencephaly is often associated with severe facial anomalies, such as hypotelorism and medial facial clefts. ${ }^{23}$ In severe cases, the orbits can be fused and a trunk-like structure called proboscis is visualized in the upper face. The first-trimester ultrasound diagnosis of cyclopia and proboscis is easy in cases in which H PE has been previously detected (Fig. 8). ${ }^{23,49}$

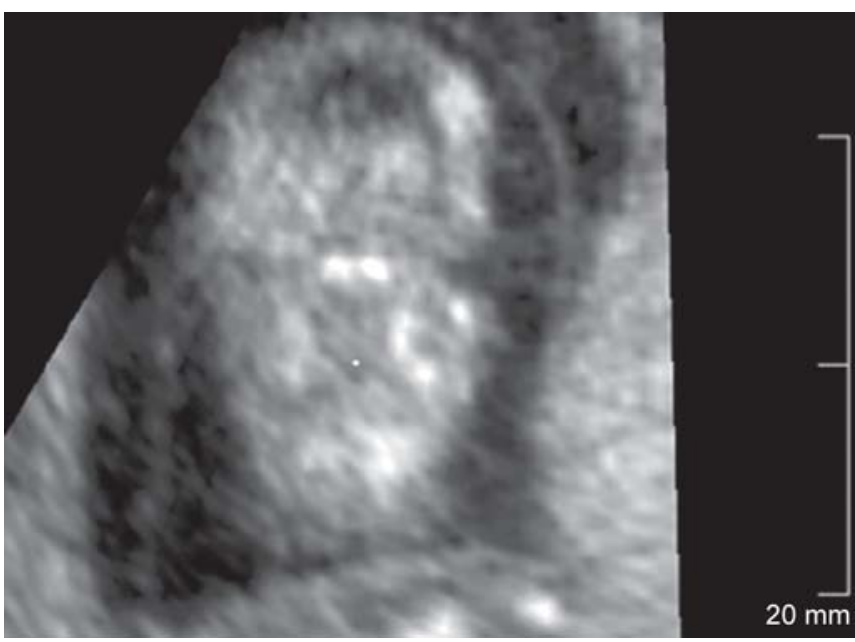

Fig. 14: Abnormal retronasal view in a 12-week fetus with absent palate and trisomy 13. Note normal nasal bones and parallel frontal processes of the maxilla

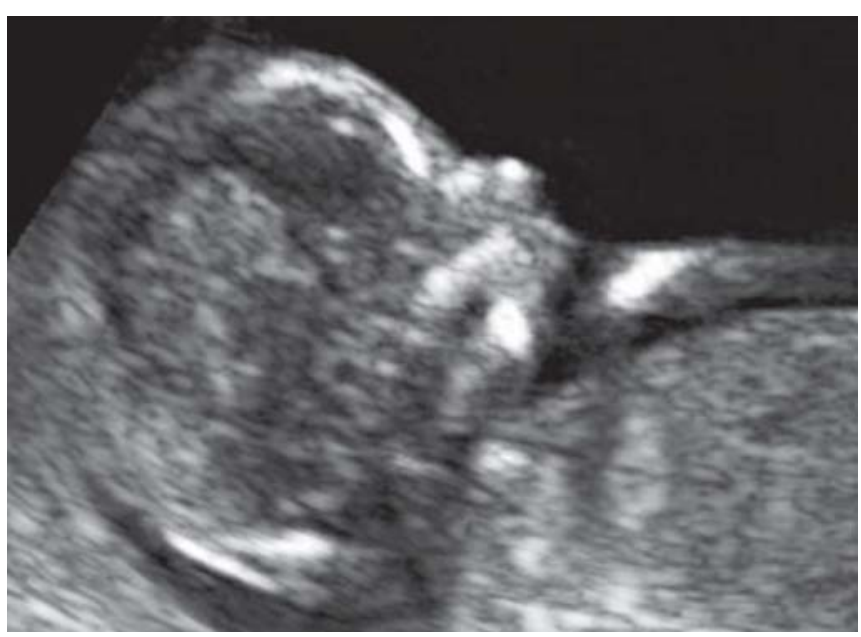

Fig. 15: Micrognathia in a 13-week fetus with trisomy 18 . Note receding chin
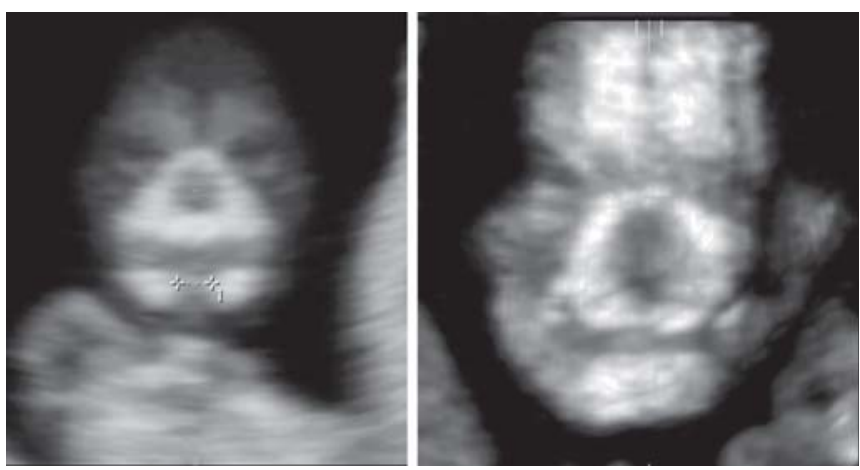

Fig. 16: Mandibular gap (between calipers). Retronasal triangle view of a normal fetus shows the normal gap between the mandibular bones (left panel) as the section crosses behind the chin. In a triploid fetus with micrognathia, the mandibular gap is absent as this section crosses through the chin (right panel)

\section{FETAL NECK}

The fetal neck, particularly its posterior aspect, is the main focus of attention when measuring the NT thickness. ${ }^{2} \mathrm{NT}$, the collection of fluid behind the fetal neck has been 
discussed in great detail in the prenatal literature and is currently the topic of thousand of papers. There is a massive body of evidence demonstrating that the NT is the best single ultrasound marker for several conditions, mainly chromosomal and structural defects. The Fetal M edicine Foundation has issued the guidelines for the correct measurement of the NT thickness and provides both educational as well as audit material for the registered operators, which are widely available to the reader. ${ }^{2,36} \mathrm{Neck}$ anomalies amenable for prenatal diagnosis include cystic hygroma, lymphangioma, teratoma, hemangioma and branchial cyst. A mong them, only two conditions are relevant in the first trimester, i.e. cystic hygroma and distended jugular lymphatic sacs, as none of the other conditions have been reported in the first trimester.

\section{Cystic Hygroma Colli}

Cystic hygroma colli is a benign lymphatic lesion that is due to failure of the lymphatic system to communicate with the venous system in the neck. It usually presents as multiloculated, fluid-filled cavities in the posterior aspect of the cervical region. ${ }^{50} \mathrm{M}$ ost if not all cases of cystic hygroma, present with a significant increase in the NT thickness (Fig. 17). The posterior ligament of the neck is easily identified in the axial plane in most cases. A ssociated findings frequently include features of fetal hydrops, such as severe subcutaneous edema and pleural effusion. Chromosomal abnormalities, such as Turner syndrome and trisomy 21 , are frequently the underlying cause. ${ }^{51}$ Therefore, prenatal karyotyping in these cases is indicated. Intrauterine lethality is high, although survivors can have a relatively normal life if alternative connections between the lymphatic and circulatory system take place in the midtrimester. ${ }^{51}$ A mong these cases, second-trimester examination usually shows nuchal fold and cardiac outflow tract anomalies. A horseshoe kidney is also a frequent associated secondtrimester finding. For screening purposes, it is important to note that differentiation between increased NT and cystic hygroma is not relevant as only the thickness is an independent predictor of aneuploidy. ${ }^{52}$

\section{Distended Jugular Lymphatic Sacs}

In contrast to cystic hygroma colli, distended jugular lymphatic sacs have only recently received some attention in the literature. ${ }^{53}$ In the first trimester, they present as local, ovoid echolucent mass in the lateral aspect of the fetal neck (Fig. 18). ${ }^{54}$ This condition is thought to be due to mesenchymal edema and abnormal lymphangiogenesis at the level of the neck and it is closely related to the development of the nuchal edema leading to increased
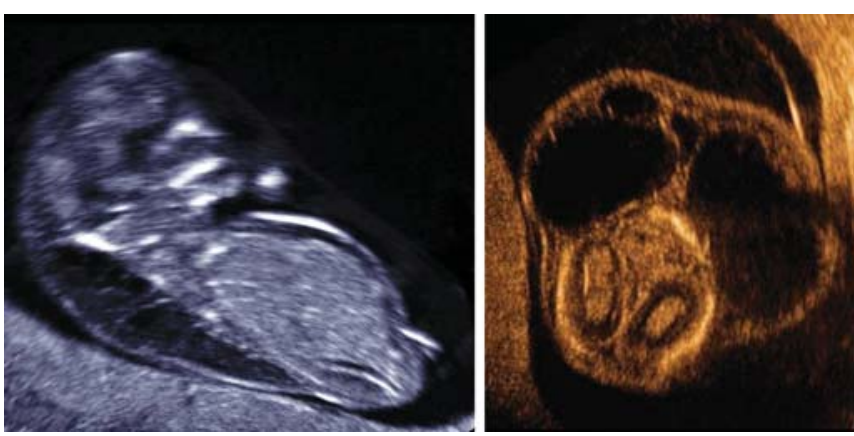

Fig. 17: First-trimester cystic hygroma colli. The nuchal translucency is enlarged and there are septations in the mass (left panel). Note bilateral cystic masses and the medial ligament of the neck (right panel) resembling aviator sunglasses ('Ray-ban' sign)
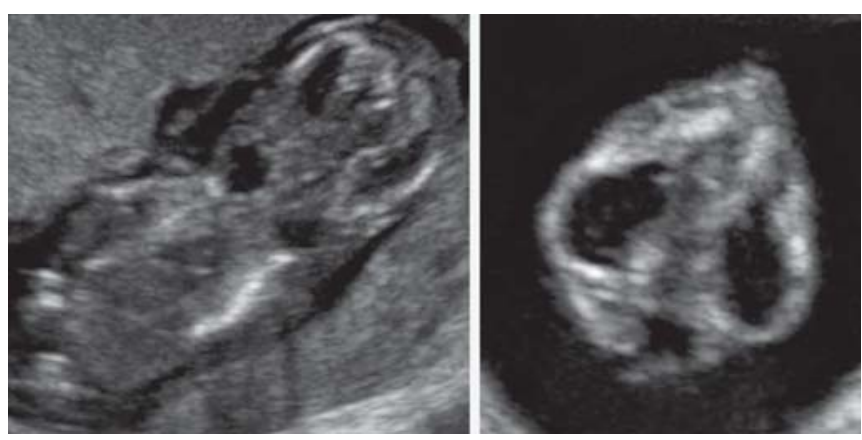

Fig. 18: First-trimester distended jugular lymphatic sacs. Note the particular location in the lateral aspect of the neck (left panel). Transverse view of the fetal neck shows the distended jugular sacs (right panel)

NT..$^{53,54}$ Indeed, transvaginal ultrasound examination of the neck in first-trimester fetuses demonstrated the presence of distended jugular lymphatic sacs in $85 \%$ of the fetuses with increased NT and in only $1.5 \%$ of the fetuses with normal NT. ${ }^{54} \mathrm{H}$ owever, careful examination of the data shows that the two fetuses considered to have normal NT in the latter group had indeed NT over the 95th percentile. Due to the clear association between distended jugular lymphatic sacs, increased NT thickness, and chromosomal abnormalities, prenatal karyotyping in these cases is indicated. ${ }^{55}$

\section{DISCUSSION}

Recognition of the normal first-trimester ultrasound anatomy of the brain, face and neck could improve the early detection of congenital abnormalities affecting these important segments of the body. Confirmation of normal ultrasound features can be reassuring for the parent-to-be whereas the detection of any abnormality of this area should prompt additional studies, including chromosomal analysis, follow-up scans and genetic counseling.

\section{REFERENCES}

1. Nicolaides K H, A zar G, Byrne D, M ansur C, M arks K. Fetal nuchal translucency: ultrasound screening for chromosomal defects in first trimester of pregnancy. BMJ 1992 A pr; 304(6831):867-869. 
2. Snijders RJM, Noble P, Sebire N, Souka A, Nicolaides KH. UK multicentre project on assessment of risk of trisomy 21 by maternal age and fetal nuchal-translucency thickness at 10-14 weeks of gestation. Fetal M edicine Foundation First Trimester Screening Group. L ancet 1998 A ug;352(9125):343-346.

3. Souka AP, Nicolaides K H. Diagnosis of fetal abnormalities at the 10-14-week scan. UItrasound Obstet Gynecol 1997 Dec;10(6):429-442.

4. Fong K W, Toi A, Salem S, Hornberger LK, Chitayat D, K eating SJ, M cAuliffe $F$, Johnson JA. Detection of fetal structural abnormalities with US during early pregnancy. Radiographics 2004 J an-Feb;24(1):157-174.

5. W eisz B , PajkrtE, J auniaux E. Early detection of fetal structural abnormalities. Reprod Biomed Online 2005 A pr; 10(4):541-553.

6. Nicolaides K H, Syngelaki A, Gil M, A tanasova V , M arkova D. $V$ alidation of targeted sequencing of single-nucleotide polymorphisms for non-invasive prenatal detection of aneuploidy of chromosomes $13,18,21, X$ and $Y$. Prenat Diagn 2013 J un;33(6):575-579.

7. Souka A P, Snijders RJ, N ovakov A, Soares W, Nicolaides KH. Defects and syndromes in chromosomally normal fetuses with increased nuchal translucency thickness at 10-14 weeks of gestation. Ultrasound Obstet Gynecol 1998 J un;11(6):391-400.

8. Souka AP, Pilalis A, Kavalakis Y, Kosmas Y, Antsaklis P, Antsaklis A. A ssessment of fetal anatomy at the 11-14-week ultrasound examination. Ultrasound Obstet Gynecol 2004 Dec;24(7):730-734.

9. Syngelaki A, Chelemen T, Dagklis T, A llan L, Nicolaides KH. Challenges in the diagnosis of fetal non-chromosomal abnormalities at 11-13 weeks. Prenat Diagn 2011 Jan;31(1): 90-102.

10. Salomon LJ, Alfirevic Z, Bilardo CM, Chalouhi GE, Ghi T, Kagan K O, Lau TK, Papageorghiou AT, Raine-Fenning NJ, Stirnemann J, et al. ISUOG practice guidelines: performance of first-trimester fetal ultrasound scan. U Itrasound O bstet Gynecol 2013 J an;41(1):102-113.

11. Goncalves LF, Espinoza J, L ee W, Romero R. Should the frontal bone be visualized in midline sagittal views of the facial profile to assess the fetal nasal bones during the first trimester? Ultrasound Obstet Gynecol 2005 Jan;25(1):90-92.

12. Chaoui R, B enoit B, M itkowska-W ozniak H, Heling KS, $\mathrm{Nicolaides} \mathrm{KH}$. A ssessment of intracranial translucency (IT) in the detection of spina bifida at the 11-13-week scan. U Itrasound Obstet Gynecol 2009 Sep;34(3):249-252.

13. Sepulveda W, W ong AE, M artinez-Ten P, Perez-Pedregosa J. Retronasal triangle: a sonographic landmark for the screening of cleft palate in the first trimester. Ultrasound O bstet Gynecol $2010 \mathrm{~J}$ an;35(1):7-13.

14. M artinez-Ten P, A diego B, Perez-Pedregosa J, I llescas T, W ong $A E$, Sepulveda W . First-trimester assessment of the nasal bones using the retronasal triangle view : a 3-dimensional sonographic study. J Ultrasound Med 2010 Nov;29(11):1555-1561.

15. Salomon LJ, Bernard JP, Duyme M, Dorion A, Ville Y. Revisiting first-trimester fetal biometry. Ultrasound Obstet Gynecol 2003 J ul;22(1):63-66.

16. Sepulveda W, Dezerega V, B e C. First-trimester sonographic diagnosis of holoprosencephaly: value of the 'butterfly' sign. J Ultrasound M ed 2004 J un;23(6):761-765.

17. Timor-Tritsch IE, Greenebaum E, M onteagudo A, Baxi L. Exencephaly-anencephaly sequence: proof by ultrasound imaging and amniotic fluid cytology. J M atern Fetal M ed 1996 Jul-Aug;5(4):182-185.
18. Sepulveda W, Sebire NJ, Fung TY, Pipi E, Nicolaides KH. Crown-chin length in normal and anencephalic fetuses at 10 to 14 weeks' gestation. Am J Obstet Gynecol 1997 A pr;176(4): 852-855.

19. J ohnson SP, Sebire NJ, Snijders RJ, Tunkel S, Nicolaides KH. UItrasound screening for anencephaly at 10-14 weeks of gestation. Ultrasound O bstet Gynecol 1997 J an;9(1):14-16.

20. Chatzipapas IK, Whitlow BJ, Economides DL. The 'M ickey Mouse' sign and the diagnosis of anencephaly in early pregnancy. Ultrasound Obstet Gynecol 1999 Mar;13(3): 196-199.

21. Cafici D, Sepulveda W . First-trimester echogenic amniotic fluid in the acrania-anencephaly sequence. J Ultrasound M ed 2003 Oct;22(10):1075-1079.

22. Sepulveda W, Sebire N J, Souka A, Snijders RJ , Nicolaides K H. Diagnosis of the M eckel-G ruber syndrome at 11 to 14 weeks' gestation. A m J Obstet Gynecol 1997 Feb;176(2):316-319.

23. Blaas H G, E riksson A G, Salvesen KA, I saksen CV , Christensen $B$, Mollerlokken G, Eik-Nes SH. Brains and faces in holoprosencephaly: pre- and postnatal description of 30 cases. Ultrasound Obstet Gynecol 2002 Jan;19(1):24-38.

24. Sepulveda W, Wong AE. First-trimester screening for holoprosencephaly with choroid plexus morphology ('butterfly' sign) and biparietal diameter. Prenat Diagn 2013 Sept 10. doi: 10.1002/pd.4235. [Epub ahead of print]

25. Sherer DM, Shane H, A nyane-Y eboa K. First-trimester transvaginal ultrasonographic diagnosis of Dandy-Walker malformation. A m J Perinatol 2001 Nov;18(7):373-377.

26. Nizard J, B ernard JP, VilleY. Fetal cystic mal formations of the posterior fossa in the first trimester of pregnancy. Fetal Diagn Ther $2005 \mathrm{M}$ ar-A pr;20(2):146-151.

27. L ee MY, W on HS, Hyun M K, Lee HY, Shim JY, Lee PR, K im A. One case of increased intracranial translucency during the first trimester associated with the D andy-W al ker variant. Prenat Diagn 2012 J un;32(6):602-603.

28. Lafouge A, Gorincour G, Desbriere R, Quarello E. Prenatal diagnosis of Blake's pouch cyst following first-trimester observation of enlarged intracranial translucency. Ultrasound Obstet Gynecol 2012 Oct;40(4):479-480.

29. Pertl $B, K$ arpf $E$, J uch $H, K$ oppin D, Stern C. A case of a transient enlargement of the intracranial translucency. Prenat Diagn 2012 Dec;32(13):1324-1325.

30. Garcia-Posada R, Eixarch E, Sanz M, Puerto B, Figueras F, Borrell A . Cisterna magna width at 11-13 weeks in the detection of posterior fossa anomalies. Ultrasound Obstet Gynecol 2013 M ay;41(4):515-520.

31. Babcook CJ, Chong BW, Salamat M S, Ellis W G, Goldstein RB. Sonographic anatomy of the developing cerebellum: normal embryology can resemble pathology. AJR A m J Roentgenol 1996 Feb;166(2):427-433.

32. Blaas HG, Eik-Nes SH. Sonoembryology and early prenatal diagnosis of neural anomalies. Prenat Diagn 2009 A pr; 29(4):312-325.

33. Illescas T, M artinez-Ten P, A diego B, B ermejo C, Sepulveda W. A bnormal appearance of the choroid plexus of the IV ventricle in the first trimester as a predictor of posterior fossa anomalies: a 3-dimensional ultrasound study. Presented at the XII W orld Congress of F etal M edicine, M arbella, Spain, 23-27 July 2013.

34. Salomon LJ, Bernard J P, Nizard J, Ville Y. First-trimester screening for fetal triploidy at 11 to 14 weeks: a role for fetal biometry. Prenat Diagn 2005 J un;25(6):479-483. 
35. L oureiro T, U shakov F, M aiz N, M ontenegro N, N icolaides K H. Lateral ventricles in fetuses with aneuploidies at 11-13 weeks' gestation. Ultrasound O bstet Gynecol 2012 Sep;40(3):282-287.

36. The Fetal Medicine Foundation. A vailable from: www. fetal medicine.com/fmf/online-education/01-11-136-week-scan. Accessed: July 2013.

37. Gullino E, Serra M, Ansaldi C, M assobrio M, Pagliano M. Bilateral cleft lip and palate diagnosed sonographically at 11 weeks of pregnancy. J Clin UItrasound 2006 Oct;34(8): 398-401.

38. Ghi T, A rcangeli T, Radico D, Cavallotti D, Contro E, Pelusi G. Three-dimensional sonographic imaging of fetal bilateral cleft lip and palate in the first trimester (letter). U Itrasound Obstet Gynecol 2009 J ul;34(1):119-121.

39. A diego B, M artinez-Ten P, Illescas T, B ermejo C, Sepulveda $W$. First-trimester assessment of the nasal bone using the retronasal triangle view. A prospective study. U Itrasound O bstet Gynecol 2013 J un 3. doi: 10.1002/uog.12525. [Epub ahead of print].

40. Sonek J, B orenstein M, Dagklis T, Persico N, Nicolaides KH. Frontomaxillary facial angle in fetuses with trisomy 21 at 1113(6) weeks. A m J Obstet Gynecol 2007 M ar;196(3):271.el-4.

41. Borenstein M, Persico N, Kagan KO, Gazzoni A, Nicolaides $\mathrm{KH}$. Frontomaxillary facial angle in screening for trisomy 21 at $11+0$ to $13+6$ weeks. Ultrasound Obstet Gynecol 2008 Jul;32(1):5-11.

42. Gabrielli S, Piva M, Ghi T, Perolo A, De Santis M S, B evini M, B onasoni P, Santini D, Rizzo N, Pilu G. Bilateral cleft lip and palate without premaxillary protrusion is associated with lethal aneuploidies. Ultrasound O bstet Gynecol 2009 Oct;34(4): 416-418.

43. Timmerman E, PajkrtE, M aas SM , Bilardo CM . Enlarged nuchal translucency in chromosomally normal fetuses: strong association with orofacial clefts. Ultrasound Obstet Gynecol $20100 \mathrm{ct} ; 36(4): 427-432$.

44. Martinez-Ten $P$, A diego B, Illescas $T$, B ermejo $C$, W ong AE, Sepulveda W. First-trimester diagnosis of cleft lip and palate using three-dimensional ultrasound. UItrasound O bstet Gynecol 2012 J ul;40(1):40-46.

45. Sepulveda W, Cafici D, B artholomew J, Wong AE, M artinezTen P. First-trimester assessment of the fetal palate: a novel application of the V olume NT algorithm. J Ultrasound M ed 2012 Sep;31(9):1443-1448.

46. Tonni G, Grisolia G, Sepulveda W. Early prenatal diagnosis of orofacial clefts: evaluation of the retronasal triangle using a new three-dimensional reslicing technique. Fetal Diagn Ther 2013;34(1):31-37.

47. Teoh M, M eagher S. First-trimester diagnosis of micrognathia as a presentation of Pierre-R obin syndrome. U Itrasound O bstet Gynecol 2003 J un;21(6):616-618.

48. Sepulveda W, W ong AE, V inals F, A ndreeva E, A dzehova N, $M$ artinez-Ten $P$. A bsent mandibular gap in the retronasal triangle view: a clue to the diagnosis of micrognathia in the first trimester. Ultrasound Obstet Gynecol 2012 Feb;39(2):152-156.
49. Sepulveda W. Monosomy $18 p$ presenting with holoprosencephaly and increased nuchal translucency in the first trimester: report of 2 cases. J Ultrasound M ed 2009 A ug; 28(8):1077-1080.

50. Chervenak FA, I saacson G, B lakemore KJ, B reg W R, Hobbins J C, B erkowitz RL, Tortora M, M ayden K, M ahoney M J. Fetal cystic hygroma. Cause and natural history. N Engl J M ed 1983 Oct;309(14):822-825.

51. M alone FD, Ball RH, Nyberg DA, Comstock CH, Saade GR, Berkowitz RL, Gross S], Dugoff L, Craigo SD, Timor-Tritsch IE, et al. FA STER Trial Research Consortium. First-trimester septated cystic hygroma: prevalence, natural history, and pediatric outcome. Obstet Gynecol 2005 A ug;106(2):288-294.

52. M olina FS, A vgidou K, Kagan K O, Poggi S, Nicolaides KH. Cystic hygromas, nuchal edema, and nuchal translucency at 1114 weeks of gestation. Obstet Gynecol 2006 M ar;107(3): 678-683.

53. Haak M C, B artelings M M, J ackson DG, W ebb S, van V ugt J M, Gittenberger-de Groot AC. Increased nuchal translucency is associated with jugular lymphatic distension. H um R eprod 2002 A pr;17(4):1086-1092.

54. Bekker M N, Haak MC, Rekoert-Hollander M, Twisk J, Van Vugt J M . Increased nuchal translucency and distended jugular lymphatic sacs on first-trimester ultrasound. UItrasound O bstet Gynecol $2005 \mathrm{M}$ ar;25(3):239-245.

55. van Heesch PN, Struijk PC, B randenburg $H$, Steegers EA, Wildschut HI. J ugular lymphatic sacs in the first trimester of pregnancy: the prevalence and the potential value in screening for chromosomal abnormalities. J Perinat Med 2008;36(6): 518-522.

\section{ABOUT THE AUTHORS}

\section{Waldo Sepulveda (Corresponding Author)}

Director, Fetal M edicine Center, Fetal M edicine Interest Group GIMEF, Santiago, Chile, Phone: +(56-2) 2458-7707, Fax +(56-2) 2458-76608, e-mail: fetalmed@yahoo.com

\section{Tamara Illescas}

Consultant, Department of Obstetrics and Gynecology, DeltaUltrasound Diagnostic Center in Obstetrics and Gynecology, M adrid Spain

\section{Begona Adiego}

Consultant, Department of Obstetrics and Gynecology, DeltaUltrasound Diagnostic Center in Obstetrics and Gynecology, M adrid Spain

\section{Pilar Martinez-Ten}

Director, Delta-Ultrasound Diagnostic Center in Obstetrics and Gynecology, Madrid, Spain 